\title{
Hemispheric amplitude asymmetries in the auditory evoked potential with monaural and binaural stimulation
}

\author{
J. L. ANDREASSI, J. J. De SIMONE, M. A. FRIEND, and P. A. GROTA \\ Baruch College, City University of New York, New York, New York 10010
}

\begin{abstract}
The present experiment examined auditory evoked potentials (AEPs) under three conditions of auditory stimulation: left ear, right ear, and the two ears simultaneously. It was hypothesized that the white-noise stimulus would result in higher amplitude AEPs in the contralateral hemisphere as compared to the ipsilateral. This was confirmed. There were no latency differences in AEPs recorded from over ipsilateral and contralateral hemispheres. The results obtained appear to provide further evidence for the predominance of the contralateral pathways of the auditory system.
\end{abstract}

Asymmetries in the evoked potential recorded from right and left hemispheres have been reported in a number of recent investigations. For example, Morrell and Salamy (1971) found that the amplitude of auditory evoked potential (AEP) components recorded from over the left hemisphere were larger than those from the right in response to auditory speech stimuli. Asymmetries have also been reported for linguistic information (Wood, Goff, \& Day, 1971), speech vs. mechanical sound-effect stimuli (Matsumiya, Tagliasco, Lombroso, \& Goodglass, 1972), contextual meaning of words (Brown, Marsh, \& Smith, 1973), and for verb and noun meanings of ambiguous words (Teyler, Roemer, \& Harrison, 1973).

The present experiment is concerned with the measurement of AEPs from both hemispheres to white-noise stimuli as a function of left and right ear presentations. The notion to perform the present experiment was derived from a series of behavioral studies in which it was indicated that subjects show superior performance in the detection of verbal stimuli presented to the right ear in a situation where both ears are stimulated simultaneously by similar stimuli (Kimura, 1961, 1967). An explanation for the superiority of the right ear in such a task (termed "dichotic" listening) is suggested by the results of electrophysiological studies of Tunturi (1946) with dogs and similar experiments by Rosenzweig (1951) with cats. Tunturi found that contralateral (crossover) pathways are greater in number and units than ipsilateral (same side) pathways, and Rosenzweig reports the same for cats. Rosenzweig has also proposed that there is a point of overlap between the ipsilateral and contralateral pathways, and that the contralateral are capable of blocking impulses along the ipsilateral paths. In terms of the dichotic listening results, it would mean that stimuli

This research was supported by the Environmental Physiology Branch of the Physiology Program, Office of Naval Research, under ONR Contract N00014-72-A-0406-0006, and ONR Contract Authority No. NR 201-053. from the right ear have priority over those from the left ear at the left hemisphere. Since the left hemisphere is concerned with language functions, the right ear digits are processed more efficiently than those arriving from the left. On the other hand, the stimuli from the left ear have priority in the right hemisphere over right ear stimuli, but this does not result in a performance difference in favor of the left ear since the right hemisphere is not concerned with language functions in the vast majority of persons.

Since the neural connections from one ear to the hemisphere on the opposite (contralateral) side are stronger than the connections to the hemisphere on the same side (ipsilateral), we reasoned that simple auditory stimuli should result in greater amplitude AEPs in the contralateral hemisphere than in the ipsilateral hemisphere. It was also thought that because of the stronger contralateral representation the latencies of major AEP components would be shorter in the contralateral as compared to the ipsilateral hemisphere.

Three conditions were established for the purpose of testing the hypotheses of this study: Condition A-auditory stimulus in left ear alone; Condition B-auditory stimulus in right ear alone; and Condition C-auditory stimulus in both ears simultaneously. The hypotheses with respect to AEP amplitudes are: (1) Condition A: amplitude of response in right hemisphere greater than left hemisphere; (2) Condition B: amplitude of response in left hemisphere greater than right hemisphere; and (3) Condition C: amplitude of response in left hemisphere equals that of right hemisphere.

\section{METHOD}

\section{Subjects}

The subjects were five male and four female graduate and undergraduate students associated with the Baruch College of the City University of New York. The ages ranged from 20 to 63 (mean of 25 years). None had auditory-system defects. All 
subjects were right-handed.

\section{Apparatus and Procedure}

Subjects were seated in an electrically shielded sound-attenuated room (IAC Chamber) while EEG was recorded from $C_{3}$ and $C_{4}$ ("Ten-Twenty" system, Jasper, 1958) with Grass silver electrodes referenced to another electrode on the subjects left ear lobe. A Beckman Type RM dynograph was used to record the EEG and a Mnemotron computer of average transients was used to obtain the averaged evoked potential. The AEP traces were drawn by a Hewlett-Packard X-Y plotter. A Grason-Statler noise generator was used to present an $80-\mathrm{dB}$ burst of white noise to the subjects over headphones. A Hunter decade/interval timer was used to time the stimulus at $200 \mathrm{msec}$. Each time a noise burst was presented, the CAT was triggered by a pulse controlled by the timer. The intensity of noise was measured at $80 \mathrm{~dB} / \mathrm{cm}^{2}$ by a General Radio sound-level meter. The interval between bursts was 1 sec.

The subject was asked to close his eyes and relax while listening to sounds coming in over headphones. He was asked to count the bursts of noise silently and to let the experimenter know that 150 presentations occurred by saying "150" aloud when this number was reached. The counting task was used to insure attentiveness to stimuli. The subject was asked not to blink his eyes or to move about excessively lest the recordings be spoiled. After answering the subject's questions and giving samples of sound as they would be presented to the left ear, the right ear, and both ears simulatenously, the experiment was begun. The EOG was recorded in pilot trials and was found to be stable under the conditions of this experiment. Therefore, it was discontinued during actual experimental trials.

The three conditions were counterbalanced over the nine subjects in a Latin-square design. Each subject started the experiment with a different condition. and this design was repeated for each group of three subjects. The subject completed three conditions, and then the three conditions were repeated again to make one complete session. Thus, each subject produced two AEPs for each of the conditions and for each of the electrode recording sites. The subject was given a 2-min rest between each trial of 150 noise bursts. The total testing time was approximately $1 \mathrm{~h}$.

\section{RESULTS AND DISCUSSION}

The averaged AEPs were analyzed with regard to the amplitude (microvolts) and latencies (milliseconds) of their P1, N2, and P2 components. The mean amplitudes and latencies were computed for each of the nine subjects from the $\mathrm{X}-\mathrm{Y}$ tracings. The $\mathrm{N} 1$ component was considered to be the first negative dip in the trace which occurred $50 \mathrm{msec}$ after the stimulus. The amplitude of the $\mathrm{N} 1$ component was measured as the vertical distance from the "baseline" to the trough of this first depression. The baseline was arbitrarily determined as the horizontal portion of the X-Y trace occurring just before the first continuous dip in the AEP trace. The Pl component was measured as the vertical distance from $\mathrm{N} 1$ to the peak of the first positive component. while N2 was measured as the vertical distance from the peak of P1 to the trough of the second major depression, and so on. While data for P1 are shown, the main analyses are for $\mathrm{N} 2$ and $\mathrm{P} 2$, the largest amplitude and most consistent components of the AEP in this experiment. The mean
Table 1

Mean Amplitude (Microvolts) for Major AEP Components of $C_{3}$ and $C_{4}$ Under Conditions $A$ (Left Ear), B (Right Ear), and $C$ (Both Ears) Across Nine Subjects

\begin{tabular}{lcccc}
\hline & AIEP Com- & \multicolumn{3}{c}{ Condition } \\
\cline { 3 - 5 } Electrode Location & ponent & A & B & C \\
\hline \multirow{3}{*}{ C $_{3}$ (Left Hemisphere) } & P1 & 1.25 & 1.18 & 1.66 \\
& N2 & 2.29 & 2.79 & 2.45 \\
& P2 & 3.79 & 2.45 & 4.58 \\
& P1 & 1.43 & 1.33 & 1.86 \\
C. (Right Hemisphere) & N2 & 2.94 & 2.45 & 2.84 \\
& P2 & 4.37 & 3.65 & 4.83 \\
\hline
\end{tabular}

amplitude data for these components is shown in Table 1 for the $\mathrm{C}_{3}$ and $\mathrm{C}_{4}$ locations. The mean latency data for these components is shown in Table 2 for $C_{3}$ and $\mathrm{C}_{4}$. The data of Tables 1 and 2 are averaged across subjects and replications. There were no differences between replications.

The amplitude data were further analyzed by tests for correlated data, one-tailed criterion (N2 and P2 data only). The $t$ ratio computed for the difference between $\mathrm{C}_{3}$ and $\mathrm{C}_{4}$ amplitude under Condition $\mathrm{A}$ yielded a value of 2.32 for $\mathrm{N} 2(\mathrm{p}<.025, \mathrm{df}=8)$ and a value of 2.18 for P2 $(\mathrm{p}<.05, \mathrm{df}=8)$. For Condition $\mathrm{B}$, the $\mathrm{C}_{3}$ amplitude was greater than that for $\mathrm{C}_{4}(\mathrm{t}=1.94, \mathrm{p}<.05$, df $=8)$. However, P2 component differences were not significant. For Condition $\mathrm{C}$, the N2 response was greater in amplitude for $\mathrm{C}_{4}$ than for $\mathrm{C}_{3}$, an unexpected result $(\mathrm{t}=3.41, \mathrm{p}<.005$, $\mathrm{df}=8)$. The $\mathrm{P} 2$ amplitudes for $\mathrm{C}_{3}$ and $\mathrm{C}_{4}$ did not differ under Condition $C$. None of the latency comparisons proved to be significantly different for any of the conditions (two-tailed criterion, $\mathrm{p}>.05 . \mathrm{df}=8$ ).

The results of this experiment provide support for Hypotheses 1 and 2, since the auditory stimulation produced larger amplitude evoked potentials in the contralateral hemispheres. Thus, it would appear that further evidence is obtained for the predominance of the contralateral pathways of the auditory system, at least with respect to response amplitude. However, one puzzling finding emerges, since the $\mathrm{N} 2$ component of the AEP recorded from the right hemisphere is greater than

Table 2

Mean Latencies (Milliseconds) for Major AEP Components from $\mathrm{C}_{3}$ and $\mathrm{C}_{4}$ Under Conditions $\mathrm{A}$ (Left Ear), B (Right Ear), and C (Both Ears) Across Nine Subjects

\begin{tabular}{lcrrr}
\hline \multirow{2}{*}{ E:kectrode Location } & $\begin{array}{c}\text { AEP Com- } \\
\text { ponent }\end{array}$ & \multicolumn{1}{c}{ A } & \multicolumn{1}{c}{ B } & \multicolumn{1}{c}{ Condition } \\
\hline \multirow{3}{*}{$C_{3}$ (Left Hemisphere) } & P1 & 93 & 80 & 81 \\
& N2 & 127 & 134 & 118 \\
& P2 & 200 & 203 & 205 \\
& P1 & 77 & 76 & 81 \\
$C_{4}$ (Right Hemisphere) & N2 & 128 & 128 & 119 \\
& P2 & 189 & 205 & 205
\end{tabular}




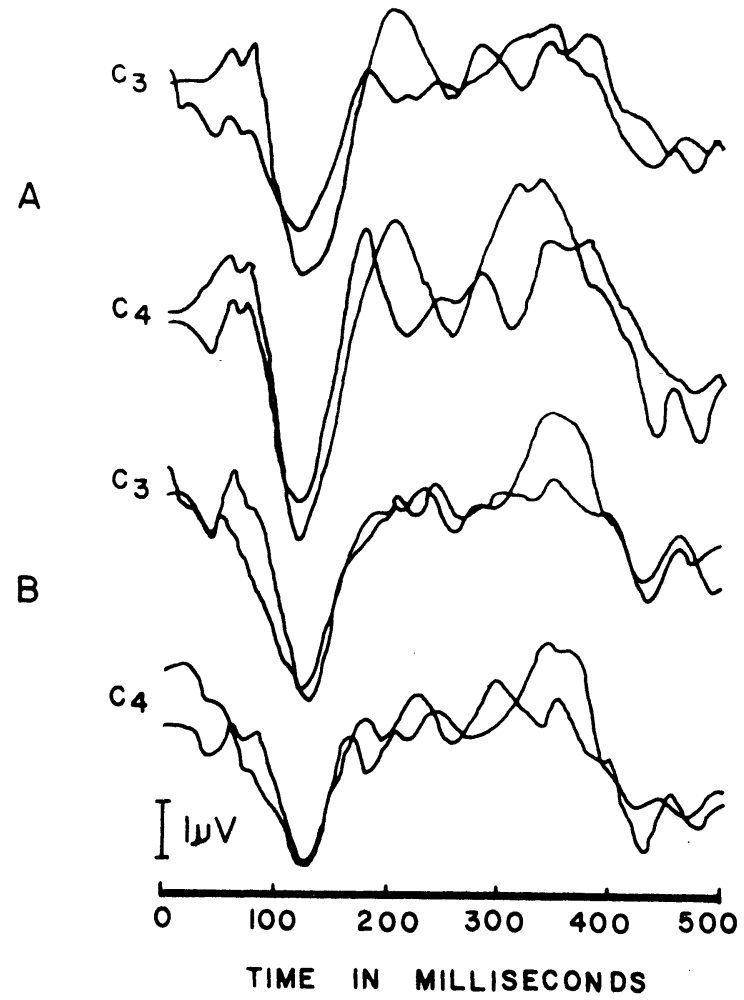

Figure 1. AEPs of one subject (L. C.) under Conditions A (left ear), B (right ear) and $C$ (both ears). Traces are based on 150 representations. Negativity is downward.

that recorded from the left hemisphere when both ears were stimulated simultaneously. An examination of Table 1 indicates that, for eight of the nine listed means, the amplitude of responses was greater for the right hemisphere than for the left hemisphere under the identical conditions of stimulation. Therefore, for these eight subjects, there seems to be a greater responsiveness to the white-noise stimulus in the right hemisphere as compared to the left. The reason for this is not known.

Figure 1 shows the raw AEP traces of one subject (L. C.) who particpated in this experiment. The results for this subject are representative and reflect the main findings of this study.

\section{REFERENCES}

Brown, W. S., Marsh, J. T., Smith, J. C. Contextual meaning effects on speech-evoked potentials. Behavioral Biology, 1973, 9, 755-761.

Jasper, $H$. H. Report of the committee on methods of examination in electroencephalography. Electroencephalography and Clinical Neurophysiology, 1958, 10, 370-375.

Kimura, D. Cerebral dominance and the perception of verbal stimuli. Canadian Journal of Psychology, 1961, 15, 166-171.

Kimura, D. Functional asymmetry of the brain in dichotic listening. Cortex, 1967, 3, 163-178.

Matsumiya, Y., Tagliasco, V., Lombroso, C. T., \& Goodlgass, H Auditory evoked response: Meaningfulness of stimuli and interhemispheric asymmetry. Science, 1972, 175, 79 0-792.

Morrell, L. K., \& Salamy, J. G. Hemispheric asymmetry of electrocortical responses to speech stimuli. Science, 1971, 174, 164-166.

Rosenzweig, M. R. Representations of the ears at the auditory cortex. American Journal of Physiology, 1951, 167, 147-158.

Teyler, T. J., Roemer, R. A., Harrison, T. F. Human scalp-recorded evoked-potential correlates of linguistic stimuli. Bulletin of the Psy chonomic Society, 1973, 1, 333-334.

Tunturi, A. R. A study on the pathway from the medial geniculate body to the acoustic cortex in the dog. American Journal of Physiology, 1946, 147, 311-319.

Wood, C. C., Goff, W. R., \& Day, R. S. Auditory evoked potentials during speech perception. Science, 1971, 173, 1248-1251.

(Received for publication July 25, 1974; revision received December 2, 1974.) 